\title{
Frequency-dependent selection on morph ratios in tristylous Lythrum salicaria (Lythraceae)
}

\author{
CHRISTOPHER G. ECKERT* ${ }^{*}$, DOMENICA MANICACCI $\$$ \& SPENCER C. H. BARRETT§ \\ $\dagger$ Department of Biology, Queen's University, Kingston, Ontario, Canada K $7 L 3 N 6$, ${ }_{+}$Centre d'Ecologie Fonctionelle et \\ Evolutive, Centre National de la Recherche Scientifique (CNRS), BP 5051, 34033 Montpellier, France and \\ $\S$ Department of Botany, University of Toronto, Toronto, Ontario, Canada, M5S $3 B 2$
}

\begin{abstract}
In the plant sexual polymorphism tristyly, disassortative mating among floral morphs should result in frequency-dependent selection leading to equal frequencies of the three morphs in populations at equilibrium. Direct evidence for frequency-dependent selection in natural populations is, however, lacking. Here we attempt to detect frequency-dependent selection in rapidly expanding populations of the invasive wetland herb Lythrum salicaria. Deterministic computer models were used to assess the expected change in morph ratios. Model results were tested with data from 24 Ontario populations each with an initially low frequency $(<0.11)$ of one morph sampled over a 5-year interval. On average, morph evenness and the frequency of the rare morph increased significantly between samples (mean frequency change $=+0.034$; range $=-0.045$ to +0.278 ). As predicted by the theoretical model, changes in both morph evenness and the frequency of the rare morph were positively correlated with initial morph frequencies. However, no evidence was obtained for expected correlations with the magnitude of the 5-year increase in population size. The results provide the first empirical demonstration of frequency-dependent selection on morph ratios in natural populations of a heterostylous plant.
\end{abstract}

Keywords: frequency-dependent selection, heterostyly, Lythrum salicaria, plant sexual polymorphisms, population size, tristyly.

\section{Introduction}

The evolutionary maintenance of sexual polymorphisms is usually ensured by frequency-dependent selection during mating. In plant sexual systems such as dioecy or distyly, for example, disassortative mating between sexual morphs generally leads to a theoretical equilibrium with equal morph ratios (Fisher, 1941). When mating type is determined by a single locus, equilibrium should be reached in one generation regardless of the initial morph frequencies. For systems with more than two mating types (e.g. multiallelic self-incompatibility, tristyly) equilibrium should be achieved more slowly (Haldane, 1936).

In tristylous populations, disassortative mating among three style morphs occurs through disassortative pollen transfer promoted by the reciprocal posi-

*Correspondence.

(C) 1996 The Genetical Society of Great Britain. tioning of stigmas and anthers among morphs, and by self- and intramorph-incompatibility (reviewed in Barrett, 1993). Frequency-dependent selection is therefore expected to drive populations to a single equilibrium with equal morph ratios (Fisher, 1941, 1944; Heuch, 1979a; Heuch \& Lie, 1985). This expectation holds for several modes of inheritance, and for both diploid and tetraploid species (Heuch \& Lie, 1985). The speed with which populations approach equilibrium will, however, depend on mating-system parameters such as disassortative mating and self-fertilization as well as life history features such as year-to-year survival and clonal propagation (Eckert \& Barrett, 1995).

Contrary to the equilibrium expectation, natural populations of several tristylous taxa exhibit significant deviations from equal morph ratios. These deviations have been interpreted with theoretical models exploring the effect of stochastic processes, life history variation and differences in fitness 
among morphs (Charlesworth, 1979; Heuch, 1979a,b, 1980; Barrett et al., 1983, 1989; Morgan \& Barrett, 1988; Eckert \& Barrett, 1992, 1995). Most of the insights arising from this work are based on the assumption that disassortative mating among morphs leads to frequency-dependent selection on morph ratios. However, empirical evidence for frequency-dependent selection in natural populations of tristylous species is largely indirect, and based on single-generation studies of mating patterns.

Direct evidence for frequency-dependent selection is lacking, because the return of morph ratios to equilibrium after perturbation has not been studied in natural populations. This is primarily because, in many tristylous taxa, temporal change in morph ratios is slowed by high levels of perenniality and restricted sexuality. For example, strongly skewed frequencies in a population of the clonal, perennial Decodon verticillatus (Lythraceae) showed no change over a 27-year period (Eckert \& Barrett, 1995). Multigenerational studies are possible in annuals. However, in the only study performed to date, Husband \& Barrett (1992) showed that the impact of disassortative mating on morph ratios in Eichhornia paniculata was negligible compared with random fluctuations caused by genetic drift.

Episodes of colonization and population expansion through sexual reproduction provide opportunities to observe frequency-dependent selection in populations of long-lived species, because high levels of seedling recruitment should allow changes in morph ratios to be observed over short time intervals. Here, we adopt this approach to investigate the impact of frequency-dependent selection on morph ratios in colonizing populations of Lythrum salicaria L. (Lythraceae). A native of Eurasia, this species has been aggressively invading wetland habitats in North America, Australia and New Zealand over the past century (Stuckey, 1980). In many portions of the adventive region, the geographical range of $L$. salicaria is expanding rapidly and individual populations often exhibit high rates of growth (Thompson et al., 1987).

In a previous study, we estimated morph ratios in 102 populations of $L$. salicaria from the adventive range in Ontario (Eckert \& Barrett, 1992). Among the trimorphic populations in this sample, a third (24 populations) exhibited skewed morph ratios involving a marked deficiency of one morph. In this study, we examine change in the morph ratios of these populations over a 5-year interval in an attempt to detect frequency-dependent selection. We begin by using computer models to predict the magnitude of short-term change in morph ratios that can be expected, and quantify how perenniality, population expansion and initial morph ratios influence the rate of change.

\section{Materials and methods}

\section{Computer models}

We examined the dynamics of frequency-dependent selection on morph ratios using a deterministic model similar to that described in Morgan \& Barrett (1988) and Eckert \& Barrett (1995). The model incorporates the mode of inheritance of tristyly found for most taxa, including L. salicaria (Lewis \& Jones, 1992). Style length is governed by the $S$ and $M$ loci, with the long-styled morph (hereafter the $\mathrm{L}$ morph) ssmm, the mid-styled (M) morph $s s M$-, and the short-styled (S) morph $S$---. Lythrum salicaria has tetrasomic inheritance at both style morph loci with no linkage, and double reduction was estimated at 10 per cent and 2.5 per cent for the $S$ and $M$ loci, respectively (Fisher \& Mather, 1943; Fisher, 1949; Fyfe, 1953). Models incorporating tetrasomic inheritance (with double reduction) gave results identical to those incorporating diploid inheritance (see also Eckert \& Barrett, 1992; Eckert et al., 1996). For generality, results are therefore presented for the diploid model. The model also incorporates life history and mating parameters likely for $L$. salicaria, with 90 per cent of all plants surviving between years, no self-fertilization or clonal propagation, and complete disassortative mating among morphs.

At the start of each run, populations had equal frequencies of two of the morphs. The third was introduced at a low frequency $\left(f_{\mathrm{i}}=0.01\right)$ and morph ratios were recorded until equilibrium $\left(f_{c}=0.333\right)$. Population growth was modelled by calculating effective annual recruitment rates $(R)$ from the proportional change in population size over each 5 -year interval $(K)$ with exponential growth, and constant survival $(I=0.90)$ :

$R=1-\frac{I}{\sqrt[5]{K}}$

$K$ was set at 1, 1.2, 2, 10 and 100 , giving $R$ s of 0.10 , $0.13,0.22,0.43$ and 0.64 , respectively. For generality, we also modelled annual populations.

\section{Population surveys}

A previous survey of 102 introduced populations of L. salicaria from southern Ontario identified 24 with

(c) The Genetical Society of Great Britain, Heredity, 77, 581-588. 
low frequencies $(<0.11)$ of one morph $($ Eckert \& Barrett, 1992). Ten of these were in eastern Ontario and 14 were in central Ontario (locations in Eckert, 1993). Morph ratios were determined by a complete population census (for seven of the smallest populations) or from a large random sample. Population size was estimated as the number of mature plants, the vast majority of which were flowering. Five years later, the 24 populations were resampled using the same methods. Complete censuses were obtained for five populations. For the 20 not completely censused in both years, there was a significant increase in sample size between samplings (median $=29$ per cent, Wilcoxon signed-rank test: $P=0.006$ ) associated with an increase in population size (see Results). Increased sampling effort could cause a spurious increase in the estimated frequency of the rare morph. However, this appears not to have occurred, because the proportional increase in sample size was not related to the observed change in frequency of the rare morph $\left(F_{1,18}=0.12\right.$, $P=0.73)$. In addition, this variable did not appear as a significant factor in any of the multiple regressions reported below.

The progress of morph ratios towards equilibrium was quantified using a measure of morph evenness ( $O$, see Husband \& Barrett, 1992), which varies from 0 for monomorphic populations to 1 for populations with equal ratios of the three morphs. We also examined changes in the frequency of the rare morph. Changes in both parameters were assessed using one-tailed paired $t$-tests. Nonparametric Wilcoxon signed-rank tests gave identical results. Significant results reported below were also robust to exclusion of extreme data points (e.g. population 10, Table 1).

Table 1 Change in morph frequencies over a 5-year interval in 24 populations of Lythrum salicaria from eastern and central Ontario

\begin{tabular}{|c|c|c|c|c|c|c|c|}
\hline Pop. no. & Rare & Freq $_{0}$ & Freq $_{5}$ & $N_{0}$ & $N_{5}$ & $O_{0}$ & $\mathrm{O}_{5}$ \\
\hline \multicolumn{8}{|c|}{ Eastern Ontario } \\
\hline 1 & $\mathrm{~L}$ & 0.071 & 0.105 & 150 & 500 & 0.517 & 0.602 \\
\hline 2 & M & 0.016 & 0.012 & 64 & 86 & 0.522 & 0.515 \\
\hline 3 & M & 0.027 & 0.025 & 2000 & 1000 & 0.517 & 0.528 \\
\hline 4 & M & 0.050 & 0.065 & 4000 & 4000 & 0.575 & 0.597 \\
\hline 5 & M & 0.060 & 0.078 & 2000 & 4000 & 0.587 & 0.617 \\
\hline 6 & M & 0.092 & 0.097 & 550 & 10000 & 0.638 & 0.643 \\
\hline 7 & M & 0.100 & 0.260 & 60 & 100 & 0.596 & 0.801 \\
\hline 8 & M & 0.107 & 0.164 & 325 & 500 & 0.650 & 0.745 \\
\hline 9 & $\mathrm{~S}$ & 0.003 & 0.000 & 400 & 500 & 0.468 & 0.499 \\
\hline 10 & $\mathrm{~S}$ & 0.077 & 0.355 & 250 & 2000 & 0.612 & 0.805 \\
\hline \multicolumn{8}{|c|}{ Central Ontario } \\
\hline 11 & $\mathrm{~L}$ & 0.074 & 0.147 & 1500 & 3000 & 0.610 & 0.715 \\
\hline 12 & $\mathrm{~L}$ & 0.105 & 0.060 & 95 & 500 & 0.657 & 0.587 \\
\hline 13 & M & 0.006 & 0.000 & 200 & 125 & 0.509 & 0.472 \\
\hline 14 & M & 0.028 & 0.054 & 400 & 400 & 0.541 & 0.557 \\
\hline 15 & M & 0.040 & 0.018 & 5000 & 5000 & 0.546 & 0.525 \\
\hline 16 & M & 0.070 & 0.127 & 600 & 900 & 0.605 & 0.686 \\
\hline 17 & M & 0.106 & 0.228 & 100 & 123 & 0.653 & 0.838 \\
\hline 18 & $\mathrm{~S}$ & 0.006 & 0.005 & 225 & 278 & 0.493 & 0.505 \\
\hline 19 & $\mathrm{~S}$ & 0.009 & 0.000 & 130 & 143 & 0.507 & 0.484 \\
\hline 20 & $\mathrm{~S}$ & 0.028 & 0.079 & 36 & 101 & 0.536 & 0.618 \\
\hline 21 & $\mathrm{~S}$ & 0.036 & 0.009 & 1000 & 2000 & 0.541 & 0.509 \\
\hline 22 & $\mathrm{~S}$ & 0.038 & 0.071 & 65 & 70 & 0.554 & 0.598 \\
\hline 23 & $\mathrm{~S}$ & 0.051 & 0.033 & 59 & 300 & 0.567 & 0.541 \\
\hline 24 & $\mathrm{~S}$ & 0.063 & 0.083 & 1300 & 1800 & 0.582 & 0.617 \\
\hline Median & & 0.051 & 0.069 & 288 & 500 & 0.561 & 0.598 \\
\hline Mean & & 0.053 & 0.087 & 855 & 1559 & 0.566 & 0.609 \\
\hline SD & & 0.034 & 0.091 & 1281 & 2304 & 0.054 & 0.107 \\
\hline
\end{tabular}

For each population, we present a code number, the identity of the rare morph, the frequency of the rare morph initially $(\text { Freq })_{0}$ and five years later $\left(\right.$ Freq $\left._{5}\right)$, initial and final estimates of population size $(N)$ and morph evenness $(O)$. Summary statistics for the entire sample appear at the bottom of the table. 
We examined the influence of several population parameters on the change in morph evenness $(O)$ and the frequency of the rare morph using multiple regression with both forward and backward elimination (Sokal \& Rohlf, 1981, pp. 661-671). Predictor variables included the initial frequency of the rare morph, initial population size, the absolute and proportional change in population size, and the proportional change in sample size between years (see above).

\section{Results}

\section{Theoretical results}

The change in morph ratios over time as well as the expected change over 5-year intervals are presented in Fig. 1. These theoretical results yield two main predictions that can be tested with our population survey data. First, the impact of frequency-dependent selection should be detectable in expanding populations. For perennial populations in which most plants survive from one year to the next and where population size is stable $(I=0.90, K=1$, $R=0.10$ ) it takes decades to attain equilibrium. In contrast, annual populations $(I=0, R=1)$ or expanding perennial populations $(I=0.90, K=100$, $R=0.64$ ) reach equilibrium in $10-20$ years. Secondly, the increase in frequency of a rare morph varies with the initial frequency of that morph. The rare morph spreads very slowly when it is infrequent $(f \approx 0.01)$ or when it is almost at equilibrium $(f>0.3)$. At intermediate frequencies $(f=0.05-$ 0.15 ), however, the expected change in morph frequency over a 5-year interval may be substantial $(>+0.05)$ when populations are expanding $(K=10-100)$.

\section{Population surveys}

Over the 5-year interval examined, 19 of the 24 populations grew in size, three populations stayed the same and two decreased (Table 1). The proportional increase averaged 175 per cent $( \pm 76 \mathrm{SE}$; range $=-50-1718 ;$ median $=44 ;$ paired $t_{23}=2.31$, one-tailed $P=0.015)$. This increase in population size was associated with significant increases in both morph evenness $(O)$ and the frequency of the rare morph. Evenness increased in 17 of 24 populations leading to a significant average increase (Table 1, Fig. $2 \mathrm{a}$; mean change $=+0.042 \pm 0.015 ;$ median $=$ +0.026 ; paired $t_{23}=2.81$, one-tailed $P=0.005$ ). Most of the increase in $O$ resulted from an increase in the frequency of the rare morph (correlation with $O: r=+0.91$ ). The rare morph increased in 14 of 24 populations which also led to a significant average increase (Table 1; Fig. 2b; mean change $\pm \mathrm{SE}=+0.034 \pm 0.014 ; \quad$ median $=+0.017 ;$ paired $t_{23}=2.38$, one-tailed $P=0.013$ ).

Single and multiple regression analysis identified the initial frequency of the rare morph as the only significant predictor of the 5-year change in either $O$
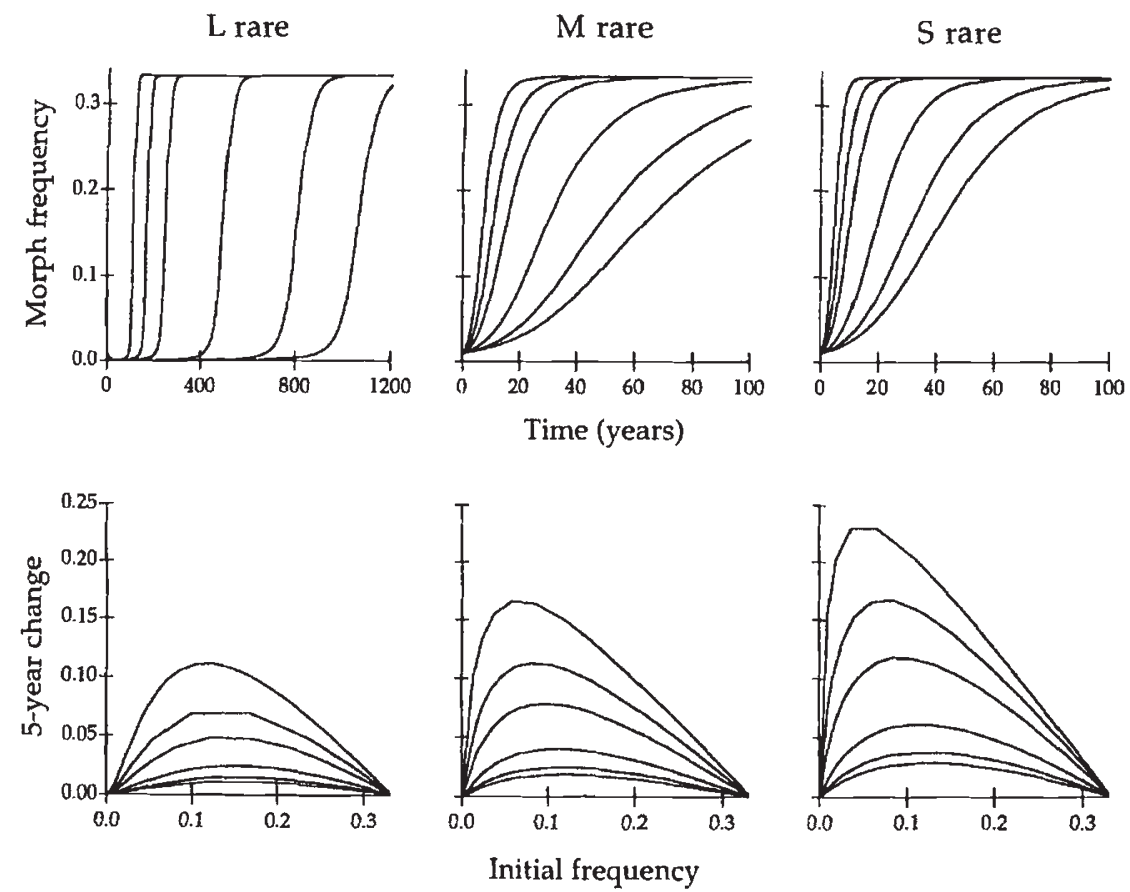

Fig. 1 Theoretical increase in frequency of a rare morph in tristylous populations (upper) and the relationship between expected change over a 5-year interval and initial frequency of the rare morph (lower). The curves, from bottom to top, correspond to per-year recruitment rates of $0.10,0.13,0.22,0.43,0.64$, and 1.00 , respectively (see Methods). 
(a) Morph evenness

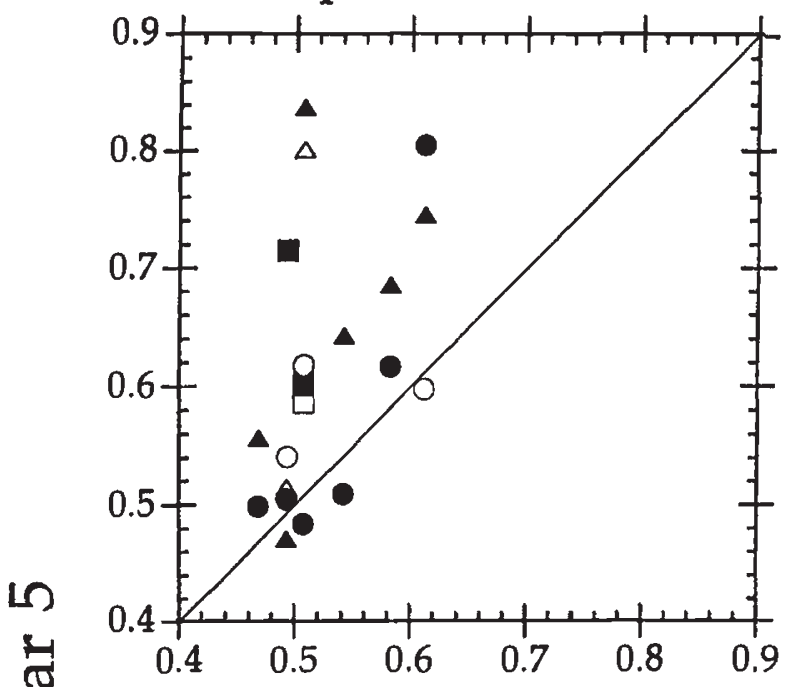

(b) Frequency of rare morph

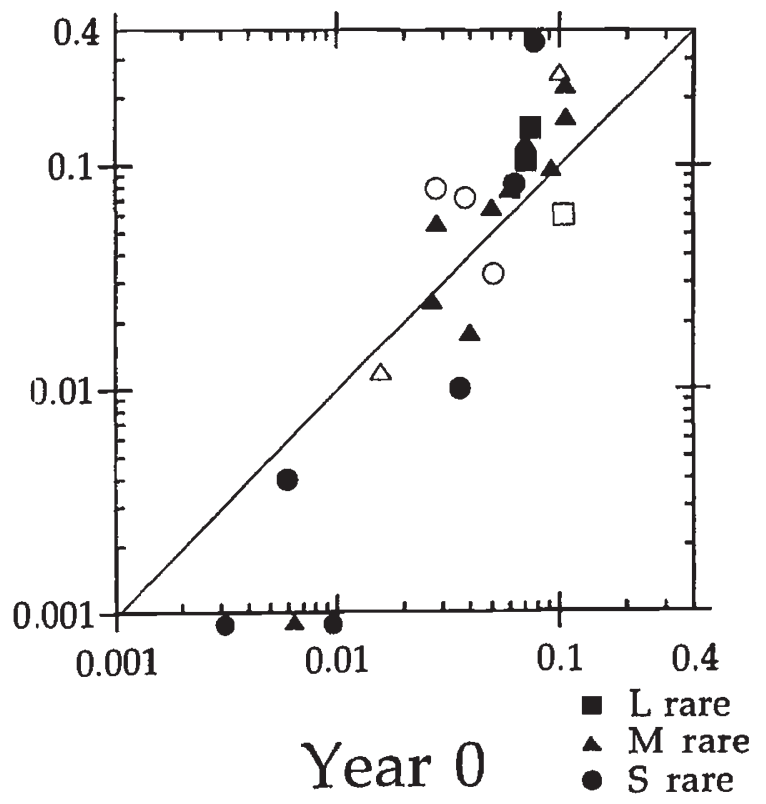

Fig. 2 Change in morph evenness (a) and the frequency of the rare morph (b) over a 5-year interval in 24 populations of tristylous Lythrum salicaria from Ontario. Populations with initially low frequencies of the $\mathrm{L}, \mathrm{M}$ or $\mathrm{S}$ morph are represented by squares, triangles and circles, respectively. Populations with fewer or greater than 100 plants are represented by open and solid symbols, respectively. Populations in which the rare morph was absent from the second sample are shown by points below the abscissa in panel B.

( $R^{2}=27$ per cent, $F_{1,22}=8.2, P=0.009$ ) or the frequency of the rare morph (Fig. 3a; $R^{2}=20$ per cent, $\left.F_{1,22}=5.6, P=0.027\right)$. Contrary to theoretical predictions, neither absolute nor proportional increase in population size was correlated with the change in either $O$ (absolute: $F_{1,22}=0.01, P=0.91$; change: $F_{1,22}=0.00, P>0.99$ ) or the frequency of the rare morph (absolute: $F_{1,22}=0.03, P=0.86$; proportional: $\quad F_{1,22}=0.38, \quad P=0.54 ; \quad$ Fig. $\left.3 b\right)$. Neither measure of population size increase was a significant predictor in multiple regressions.

\section{Discussion}

Frequency-dependent selection is the principal evolutionary force maintaining sexual polymorphisms in populations of plants and animals. In tristylous populations, frequency-dependent selection results from disassortative mating among style morphs which drives populations towards a single equilibrium with equal frequencies of the three morphs, and is the critical factor maintaining tristyly in the face of genetic drift (Heuch, 1980; Barrett et al., 1989; Eckert \& Barrett, 1992). However, direct evidence for frequency-dependent selection in natural populations of tristylous plants is lacking (see Husband \& Barrett, 1992). Its operation has been indirectly inferred from the occurrence of strong self- and intramorph-incompatibility in most tristylous species (Ganders, 1979; Eckert \& Barrett, 1992) as well as experimental observations of disassortative pollen transfer among morphs (Barrett \& Glover, 1985; Lloyd \& Webb, 1992). Disassortative mating has also been demonstrated through the analysis of morph ratios in progeny arrays from natural populations of self-incompatible Lythrum salicaria (Fisher \& Mather, 1943; Ågren \& Ericson, 1995) and Oxalis alpina (Weller, 1986) as well as self-compatible Eichhornia paniculata (Barrett et al., 1987) and Decodon verticillatus (Eckert \& Barrett, 1994).

Our results provide the first evidence for frequency-dependent selection on morph ratios in natural tristylous populations. Morph evenness and the frequency of the rare morph both showed a slight but statistically significant increase over a 5-year interval in 24 populations of Lythrum salicaria. Empirical demonstrations of frequencydependent selection in natural populations are few (Endler, 1986). Tristylous populations would appear to provide good opportunities for detecting this mode of selection because, theoretically, populations should progress in a predictable fashion towards a single global genotypic and phenotypic equilibrium (Heuch \& Lie, 1985; Eckert \& Barrett, 1995). Moreover, progress towards this equilibrium is unaffected by the details of how the polymorphism is inherited (see above). 
(a)

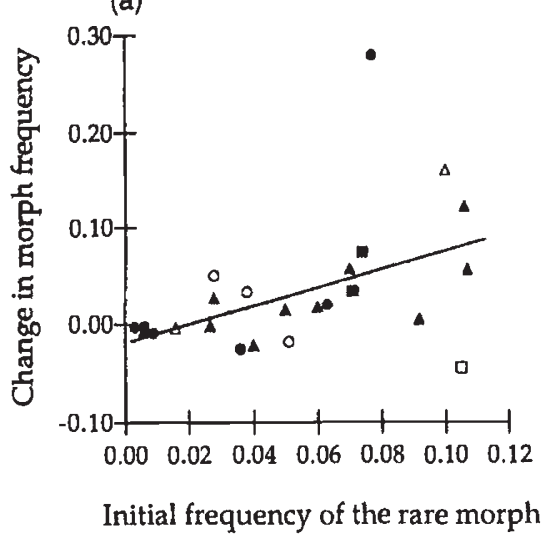

(b)

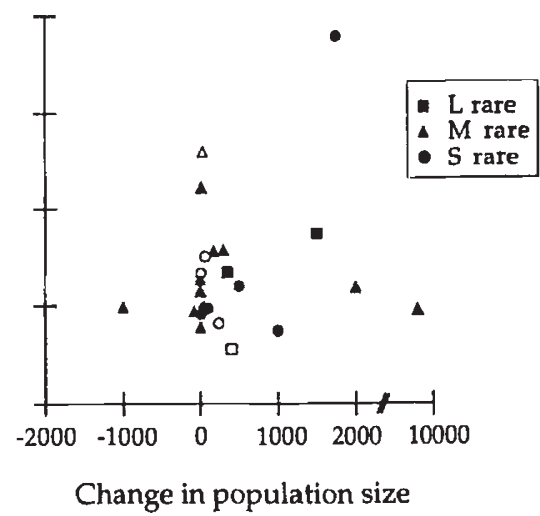

Fig. 3 Change in the frequency of the rare morph over 5 years in relation to initial frequency (a) and change in population size (b). Populations with initially low frequencies of the $\mathrm{L}, \mathrm{M}$ or $\mathrm{S}$ morph are represented by squares, triangles and circles, respectively. Populations with fewer or greater than 100 plants are represented by open and solid symbols, respectively.
Our success at detecting frequency-dependent selection in Lythrum salicaria was influenced by four main factors. First, the species possesses strong heteromorphic incompatibility which enforces disassortative mating among morphs (Darwin, 1877; Stout, 1923; O'Neil, 1994; Ottenbreit \& Staniforth, 1994; D. Manicacci \& S. C. H. Barrett, unpublished data). In contrast, theoretical and empirical work on a related self-compatible, tristylous species, Decodon verticillatus, showed that departures from disassortative mating and partial self-fertilization can greatly slow the approach to equilibrium (Eckert \& Barrett, 1995).

Secondly, our sample of populations spanned the range of initial morph ratios over which frequencydependent selection could be observed. The initial frequency of the rare morph varied from $0.003-0.107$. The theoretical results presented above indicate that frequency-dependent selection is most easily detected at moderate frequencies of the rare morph (0.05-0.15), but should have little short-term effect in populations that are either too close to or too far away from equilibrium. This prediction was supported by a positive correlation between the initial frequency of the rare morph and its 5-year increase (Fig. 3a).

Thirdly, large-scale surveys of morph-ratio variation have demonstrated that genetic drift may strongly influence morph ratios in natural populations of L. salicaria (Eckert \& Barrett, 1992; Eckert et al., 1996). Although drift probably accounts for the substantial variation in morph-ratio change among populations in our sample as well as for the loss of the rare morph in three populations with very low initial frequencies (Fig. 2b), it was not sufficiently strong to obscure entirely the average shortterm progress of morph ratios towards equilibrium. Computer simulations of morph-ratio variation in finite populations suggest that this is probably because most of the populations in this study were large enough (range $=36-5000$, median $=288$ ) to be relatively resistant to the short-term effects of genetic drift (Heuch, 1980; Barrett et al., 1989; Eckert \& Barrett, 1992).

Finally, our theoretical results suggest that the high levels of recruitment in the rapidly expanding populations examined in this study alleviated the constraining effect of $L$. salicaria's perennial life history on temporal change in morph frequencies. This, however, appears to be at odds with our finding of no relation between the 5-year increase in population size and the change in frequency of the rare morph. There are two possible explanations for this.

In our model, we simulated an exponential increase in population size with recruitment of new individuals every year. Uneven yearly recruitment will reduce the effect of frequency-dependent selection. In the extreme case, the observed increase in population size may have occurred in a single year thereby reducing the potential action of selection to a single expansion event. Even in rapidly expanding populations, change in the frequency of the rare morph over a 1-year interval is always small (theoretical results not shown). As seedling establishment in L. salicaria appears to be strongly dependent on disturbance and water levels (Thompson et al., 1987; Mal et al., 1992), episodic recruitment may be a regular feature of the population dynamics of this species. Similar ecological constraints on recruitment have been implicated in controlling morphfrequency change in another tristylous aquatic, Pontederia cordata (Morgan \& Barrett, 1988).

Our model also assumes that mating occurs randomly among compatible mates thus encouraging the spread of a rare morph. In populations with low 
initial frequencies of the rare morph this form of panmixia requires extensive intrapopulation pollen flow. In Ontario, however, L. salicaria is mainly pollinated by honeybees (Apis mellifera) and bumble bees (Bombus spp.), which do not move large distances between foraging bouts (Levin, 1970; C. G. Eckert, personal observation) and are therefore unlikely to mediate random pollen transfer within populations. The dampening effect of local mating on morph-ratio change will depend on the spatial distribution of the rare morph within populations. This uncontrolled aspect of population structure may have weakened the correlation between population growth and the progress towards equilibrium. Spatially explicit models incorporating population structure may be required for a more realistic assessment of the dynamics of morph-frequency change in tristylous populations.

\section{Acknowledgements}

We thank J. D. Thompson and P. D. Taylor for comments on the manuscript; the Queen's University Biological Station for support in the field; the French Ministry of Foreign Affairs for a Lavoisier Post-Doctoral Grant to D.M.; the Queen's University Faculty of Arts and Science for a Visiting Scholar's Award to D.M.; and the Natural Sciences and Engineering Research Council of Canada (NSERC) for research grants to C.G.E. and S.C.H.B.

\section{References}

Ågren, J. AND ERICSON, L. 1995. Population structure and morph-specific fitness differences in tristylous Lythrum salicaria. Evolution, 50, 126-139.

BARRETT, S. C. H. 1993. The evolutionary biology of tristyly. In: Futuyma, D. \& Antonovics, J. (eds), Oxford Surveys in Evolutionary Biology, pp. 283-326. Oxford University Press, Oxford, U.K.

BARRETT, S. C. H. AND GloVer, D. E. 1985. On the Darwinian hypothesis of the adaptive significance of tristyly. Evolution, 39, 766-774.

BARRETT, S. C. H., PRICE, S. D. AND Shore, J. s. 1983. Male fertility and anisoplethic population structure in tristylous Pontederia cordata (Pontederiaceae). Evolution, 37, 745-759.

BARRETT, s. C. H., BROWN, A. H. D. AND SHORE, J. s. 1987. Disassortative mating in tristylous Eichhornia paniculata (Pontederiaceae). Heredity, 58, 49-55.

BARRETT, S. C. H., MORGAN, M. T. AND HUSBAND, B. C. 1989. The dissolution of a complex genetic polymorphism: the evolution of self-fertilization in tristylous Eichhornia paniculata. Evolution, 43, 1398-1416.
CHARLESWORTH, D. 1979. The evolution and breakdown of tristyly. Evolution, 33, 486-498.

DARWIN C. 1877. The Different Forms of Flowers on Plants of the Same Species. John Murray, London.

ECKERT, C. G. 1993. The Evolutionary Maintenance of a Sexual Polymorphism in Clonal Decodon verticillatus (Lythraceae). Ph.D. Thesis, University of Toronto.

ECKERT, C. G. AND BARRETT, s. C. H. 1992. Stochastic loss of style morphs from populations of tristylous Lythrum salicaria and Decodon verticillatus (Lythraceae). Evolution, 46, 1014-1029.

ECKERT, C. G. AND BARRETT, s. C. H. 1994. Post-pollination mechanisms and the maintenance of outcrossing in selfcompatible Decodon verticillatus. Heredity, 72, 396-411.

ECKERT, C. G. AND BARRETT, s. C. H. 1995. Style morph ratios in tristylous Decodon verticillatus (Lythraceae): selection versus historical contingency. Ecology, 76, 1051-1066.

ECKERT, C. G., MANICACCl, D. AND BARRETT, S. C. H. 1996. Genetic drift and founder effect in native versus introduced populations of an invading plant, Lythrum salicaria (Lythraceae). Evolution, 50, 1523-1530.

ENDler, J. A. 1986. Natural Selection in the Wild. Princeton University Press, Princeton, NJ.

FISHER, R. A. 1941. The theoretical consequences of polyploid inheritance for the mid style form in Lythrum salicaria. Ann. Eugen., 11, 31-38.

FISHER, R. A. 1944. Allowance for double reduction in the calculation of genotype frequencies with polysomic inheritance. Ann. Eugen., 12, 169-171.

FISHER, R. A. 1949. The linkage problem in a tetrasomic wild plant, Lythrum salicaria. Proc. 8th Int. Congr. Genetics, Hereditas suppl., 223-233.

FISHER, R. A. AND MATHER, K. 1943. Inheritance of style length in Lythrum salicaria. Ann. Eugen., 12, 1-23.

FYFE, v. C. 1953. Double reduction at the mid locus in Lythrum salicaria. Heredity, 7, 285-292.

GANDERS, F. R. 1979. The biology of heterostyly. N. Z.J. Bot., 17, 607-635.

HALDANE, J. B. S. 1936. Some natural populations of Lythrum salicaria. J. Genet., 32, 393-397.

HEUCH, 1. 1979a. Equilibrium populations of heterostylous plants. Theor. Pop. Biol., 15, 43-57.

HEUCH, 1. 1979b. The effect of partial self-fertilization on type frequencies in heterostylous plants. Ann. Bot., 44, 611-616.

HEUCH, 1. 1980. Loss of incompatibility types in finite populations of the heterostylous plant Lythrum salicaria. Hereditas, 92, 53-57.

HEUCH, 1. AND LIE, R. T. 1985. Genotype frequencies associated with incompatibility systems in tristylous plants. Theor. Pop. Biol., 27, 318-336.

HUSBAND, B. C. AND BARRETT, s. C. H. 1992. Genetic drift and the maintenance of style length polymorphism in tristylous populations of Eichhornia paniculata (Pontederiaceae). Heredity, 69, 440-449.

LEVIN, D. A. 1970. Assortative pollination in Lythrum. Am. J. Bot., 57, 1-5.

LEWIS, D. AND JONES, D. A. 1992. The genetics of hetero-

(c) The Genetical Society of Great Britain, Heredity, 77, 581-588. 
styly. In: Barrett, S. C. H (ed.) Evolution and Function of Heterostyly, pp. 129-150. Springer-Verlag, Berlin.

LLOYD, D. G. AND WEBB, C. J. 1992. The selection of heterostyly. In: Barrett, S. C. H (ed.) Evolution and Function of Heterostyly, pp. 179-208. Springer-Verlag, Berlin.

MAL, T. K., LOVETT DOUST, J., LOVETT DOUST, L. AND MUlligan, G. A. 1992. The biology of Canadian weeds. 100. Lythrum salicaria. Can. J. Plant Sci., 72, 1305-1330.

MORGAN, M. T. AND BARRETT, S. C. H. 1988. Historical factors and anisoplethic population structure in tristylous Pontederia cordata: a reassessment. Evolution, 42, 496-504.

O'NEIL, P. 1994. Genetic incompatibility and offspring quality in the tristylous plant Lythrum salicaria (Lythraceae). Am. J. Bot., 81, 76-84.

OTTENBREIT, K. A. AND STANIFORTH, R. J. 1994. Crossability of naturalized and cultivated Lythrum taxa. Can. J. Bot., 72, 337-341.

SOKAL, R. R. AND ROHLF, F. J. 1981. Biometry, 2nd edn. Freeman, New York.

Stout, A. B. 1923. Studies of Lythrum salicaria. I. The efficiency of self-pollination. Am.J. Bot., 10, 440-449.

STUCKEY, R. L. 1980. The distributional history of Lythrum salicaria (purple loosestrife) in North America. Bartonia, 100, 3-30.

THOMPSON, D. Q., STUCKEY, R. L. AND THOMPSON, E. B. 1987. Spread, impact, and control of purple loosestrife (Lythrum salicaria) in North American wetlands. U.S. Fish and Wildlife Service. Fish and Wildlife Research 2.

WELLER, s. G. 1986. Factors influencing frequency of the mid-styled morph in tristylous populations of Oxalis alpina. Evolution, 40, 279-289. 